\title{
NME FAMILY AND DETERMINATION OF EGG QUALITY, NEW INSIGHTS FROM THE ZEBRAFISH DANIO RERIO
}

\author{
Desvignes T. ${ }^{* \circ}$, Fauvel C. ${ }^{\circ}$, Fostier A.*, Bobe J.* \\ *Sex differentiation and oogenesis group, INRA, SCRIBE UR 1037, Rennes F-35042, France, email: \\ Thomas.Desvignes@ rennes.inra.fr \\ ${ }^{\circ}$ Biology of Marine Organisms, IFREMER, Palavas-les-flots F-34250, France
}

\section{Background:}

Early development of fish relies on maternal gene products (i.e. mRNA and proteins) stored into the oocyte during oogenesis as the genome of the embryo does not start to be transcriptionally active until the MZT (Maternal-to-Zygotic Transition) that occurs during the Mid-Blastula Transition (MBT). A previous genomic analysis of fish eggs pointed out the Nme family as being linked to the developmental potential of the egg in Atlantic sea bass (Dicentrarchus labrax) [1]. The Nme family is known to be involved in key cellular processes such as cell proliferation and differentiation. It has also been extensively studied in relationship with the metastatic potential of tumors in cancer research [2]. In contrast, very little is known about the role of the Nme family during early development of non-mammalian vertebrate species despite its known importance in Drosophila development. The aim of the present work was thus (i) to characterize the Nme gene family in fish, (ii) to study the expression of nme genes during oogenesis and early development, and (iii) to characterize its participation in the molecular mechanisms that define the developmental potential of the egg.

\section{Methods:}

After an extensive characterization of the evolutionary history of the Nme gene family in metazoans with special attention for the vertebrates and teleosts, the ten members of the gene family were studied in a panel of eight zebrafish (Danio rerio) tissues by real time PCR (QPCR). Transcripts showing a predominant ovarian expression were subsequently monitored throughout oogenesis and early development by QPCR and in situ hybridization. Whenever possible,

Fig.1. Tissue expression of nme genes in zebrafish.

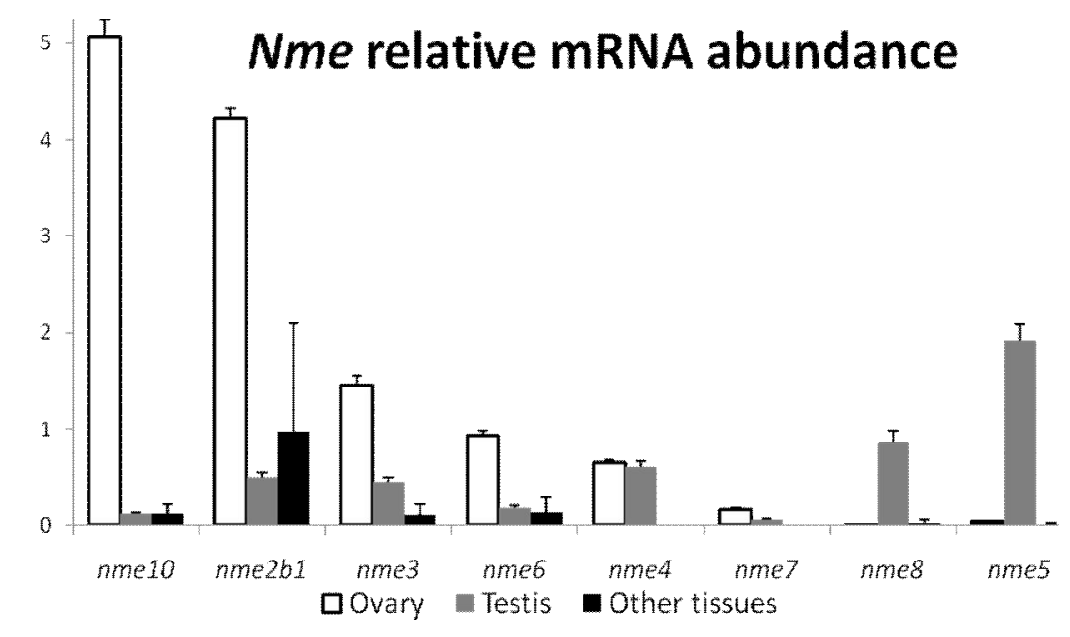

Fig.2. Nme gene family evolutionary history. $1 R$ and $3 R$ refer to the first and third round of whole genome duplication respectively. CD stands for Cis-duplication of the corresponding gene. Redrawn from Desvignes et al 2009 and 2010.

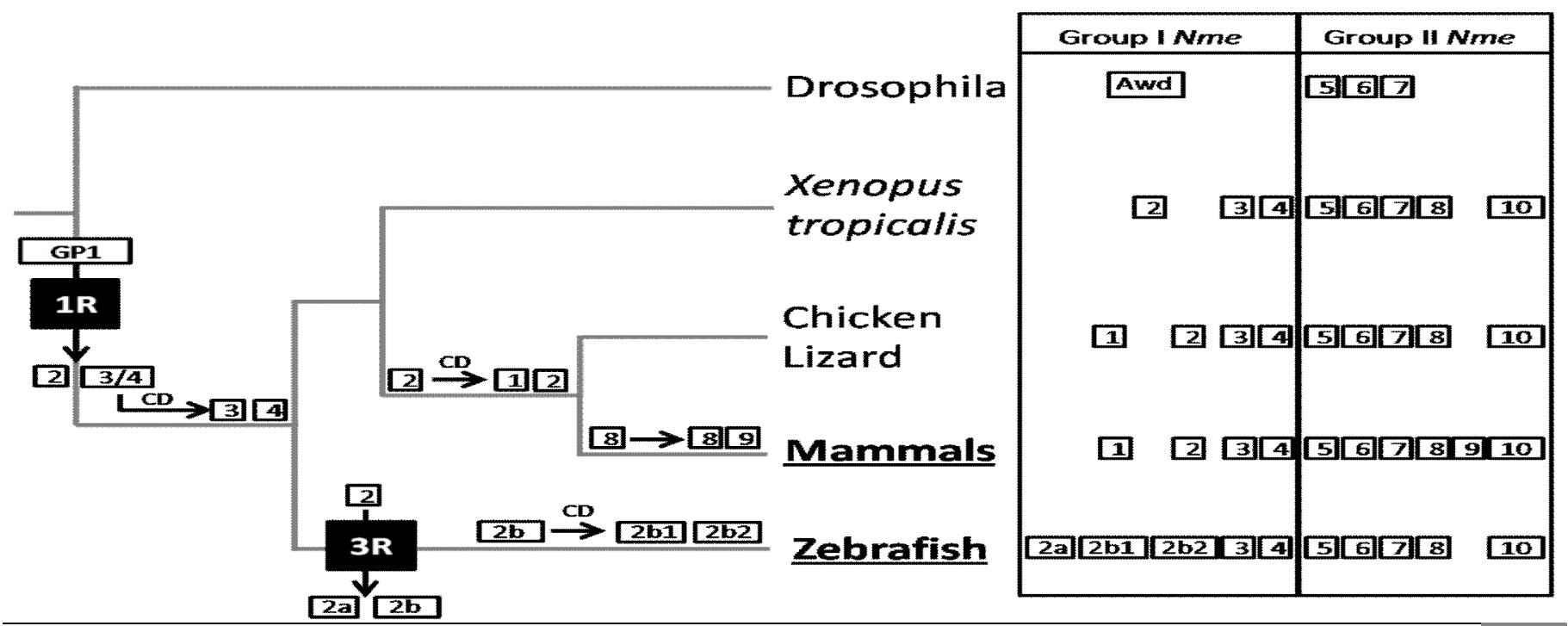


the corresponding protein products were studied by

Western Blot and immunostaining. Finally, knockdown experiments directed against maternally-inherited nme transcripts were carried out using injection of antisense morpholino oligos (MOs) into the embryo at 1cell stage in order to study the functional implication of the corresponding proteins in embryonic development.

\section{Results and Discussion:}

First, the evolutionary characterization of the Nme family revealed that among the 10 nme genes, 7 are common to all vertebrates while the 3 othergenes underwent independent duplication events in the teleost and tetrapods radiations (Fig. 1) $[3,4]$.

Interestingly, the tissue expression survey revealed that the 10 nme genes are expressed in the zebrafish gonads (Fig. 2). Whereas nme5 and nme8 are testispredominant, in agreement with existing data in mammals [2], most of the 8 other genes are predominantly expressed in the ovary [3]. Moreover, oogenesis and early development expression survey showed that 3 nme genes are maternally-inherited as mRNAs in the zebrafish egg [5]. Another nme gene, highly expressed during the first steps of oogenesis is likely to be maternally-inherited in the egg as a protein. Finally, knock-down experiments using MOs led to lower embryonic survival during the first $24 \mathrm{~h}$ of development, important morphological defects, and decreased hatching rates in injected embryos compared to embryos injected with a negative control $\mathrm{MO}$ at the same concentration.

\section{Conclusion:}

In addition to the already documented implication of Nme genes in key cellular processes for cell proliferation and differentiation, the present study clearly demonstrates a predominant ovarian expression of several nme genes for the first time in any vertebrate species. Together the maternal profiles of several nme genes and the results of the knock down study strongly suggest an important role for oocyte developmental competence in fish. Given the ancient origin of the family in metazoans, a significant role of the Nme family in reproductive process can also be anticipated in the teleost lineage.

\section{References:}

[1]CRESPEL A, RIME H, FRABOULET E, BOBE J, FAUVEL C. 2008. Egg quality in domesticated and wild seabass (Dicentrarchus labrax): A proteomic analysis. Cybium, 32(2) suppl.: 205.

[2]BOISSAN M, DABERNAT S, PEUCHANT E, SCHLATTNER U, LASCU I, LACOMBE ML. 2009.The mammalian Nm23/NDPK family: from metastasis control to cilia movement. Mol. Cell Biochem., 329: 51-62.

[3]DESVIGNES T, PONTAROTTI P, FAUVEL C, BOBE J. 2009.Nme protein family evolutionary history, a vertebrate perspective. BMC. Evol. Biol., 9: 256.

[4]DESVIGNES T, PONTAROTTI P, BOBE J. 2010.Nmegene family evolutionary history reveals pre-metazoan origins and high conservation between humans and the sea anemone, Nematostella vectensis. PLoS ONE, 5: e15506.

[5]DESVIGNES T, FAUVEL C, BOBE J. 2011. The nme gene family in zebrafish oogenesis and early development. N-S Arch Pharmacol, in press. 